\title{
Genetic Variability of Lactoferrin Content Estimated by Mid-Infrared Spectrometry in Bovine Milk
}

\author{
H. Soyeurt, ${ }^{*}{ }^{1}$ F. G. Colinet,‡ V. M.-R. Arnould,‡ P. Dardenne,§ C. Bertozzi,\# R. Renaville,‡ \\ D. Portetelle, $\ddagger$ and N. Gengler* \\ ${ }^{*}$ Animal Science Unit, Gembloux Agricultural University, B-5030 Gembloux, Belgium \\ †Fonds pour la Formation à la Recherche dans l'Industrie et l'Agriculture (FRIA), B-1000, Brussels, Belgium \\ $\ddagger$ Animal and Microbial Biology Unit, Gembloux Agricultural University, B-5030 Gembloux, Belgium \\ §Walloon Agricultural Research Centre, Quality Department, B-5030 Gembloux, Belgium \\ \#Walloon Breeding Association, B-5530 Ciney, Belgium \\ |National Fund for Scientific Research, B-1000 Brussels, Belgium
}

\section{ABSTRACT}

The effects of lactoferrin (LF) on the immune system have already been shown by many studies. Unfortunately, the current methods used to measure LF levels in milk do not permit the study of the genetic variability of lactoferrin or the performance of routine genetic evaluations. The first aim of this research was to derive a calibration equation permitting the prediction of $\mathrm{LF}$ in milk by mid-infrared spectrometry (MIR). The calibration with partial least squares on 69 samples showed a ratio of standard error of cross-validation to standard deviation equal to 1.98. Based on this value, the calibration equation was used to establish an LF indicator trait (predicted LF; pLF) on a large number of milk samples $(n=7,690)$. A subsequent study of its variability was conducted, which confirmed that stage of lactation and lactation number influence the overall pLF level. Small differences in mean pLF among 7 dairy breeds were also observed. The pLF content of Jersey milk was significantly higher than that in Holstein milk. Therefore, the choice of breed could change the expected LF level. Heritability estimated for pLF was 19.7\%. The genetic and phenotypic correlations between somatic cell score and pLF were 0.04 and 0.26 , respectively. As somatic cell score increases in presence of mastitis, this observation seems to indicate that $\mathrm{pLF}$, or a function of observed $\mathrm{pLF}$, compared with expected LF might have potential as an indicator of mastitis. The negative genetic correlation $(-0.36)$ between milk yield and pLF could indicate an undesirable effect of selection for high milk production on the overall LF level.

Key words: lactoferrin, milk, mid-infrared spectrometry, genetic

Received December 17, 2006.

Accepted April 27, 2007.

${ }^{1}$ Corresponding author: soyeurt.h@fsagx.ac.be

\section{INTRODUCTION}

First isolated from human and bovine milk and characterized in the 1960 s, lactoferrin $(\mathbf{L F})$ is a highly positively charged $78-\mathrm{kDa}$, bilobal, iron-binding glycoprotein. Lactoferrin belongs to the transferrin gene family (Mead and Tweedie, 1990; Ward et al., 2005) and consists of a single 690-AA polypeptide chain folded into 2 lobes that show sequence homology with each other (Pierce et al., 1991). Each lobe presents a binding site for a ferric ion along with a synergistic anion, usually bicarbonate (Brock, 1995; Baker and Baker, 2004, 2005).

Lactoferrin is found in most biological fluids including colostrum ( 1.5 to $5 \mathrm{~g} / \mathrm{L})$, mature milk $(0.1 \mathrm{~g} / \mathrm{L})$, tears (2 g/L), and blood (1 mg/L) (Gaunt et al., 1980; Farnaud and Evans, 2003; Baker and Baker, 2004, 2005). Unlike other proteins found in milk, LF is secreted in abundance by mammary epithelial cells throughout mammary development, including the nonpregnant, nonlactating, and involuting stages. This protein is present naturally in higher concentrations during the later prepartum lactating and dry periods $(0.25$ to $0.40 \mathrm{~g} / \mathrm{L})$ than in early lactation stages (Hagiwara et al., 2003; Baumrucker et al., 2005; Pugovel et al., 2005). Lactoferrin can also be released by polymorphonuclear neutrophils during inflammation (20 to $80 \mathrm{~g} / \mathrm{L}$; Kutila et al., 2004).

Thus, because of its actions, LF is important to maintain a good immune system. Several roles allotted to LF are clearly related to its reverse iron-binding properties (Mead and Tweedie, 1990; Baker and Baker, 2004). Lactoferrin seems to act as a general antibacterial molecule (Baker, 2005) and seems to present antifungal effects against Candida spp. in combination with fluconazole, and antiviral activities by inhibiting virus replication after viral infection and by competing for host cell molecules that the virus uses as a (co)receptor (Farnaud and Evans, 2003). Lactoferrin might also be involved in host defense mechanisms (Ward et al., 2005). In fact, 
this molecule is associated with the activation of natural killer cells, leukocytes, and monocytes, maturation of splenic B cells, and stimulation of cellular growth (Baveye et al., 1999; Baumrucker, 2000; Ward et al., 2005). Lactoferrin has been shown to modulate the inflammatory process, mainly by preventing the release of cytokines from monocytes and by regulating the proliferation and differentiation of immune cells (Farnaud and Evans, 2003). By its actions, the natural production of LF could be a good indicator of resistance to mastitis, and LF content could be used to detect mastitis in dairy cows. In a similar way to SCC, a high LF concentration may indicate clinical or subclinical mastitis compared with the normal LF level in milk produced by a specific cow. Indeed, although LF is present in low concentrations $(0.1$ to $0.4 \mathrm{~g} / \mathrm{L})$ in the milk of healthy cows, $\mathrm{LF}$ concentrations in milk can reach as high as $2.3 \mathrm{~g} / \mathrm{L}$ during clinical mastitis (Kutila et al., 2004).

Use of reference analyses such as ELISA or immunodiffusion methods to measure the LF content in bovine milk is time consuming and requires skilled staff. Therefore, these methods are not feasible for routine milk recording. This lack of data currently limits the possibility of studying $\mathrm{LF}$ and its potential use as an indicator trait of mastitis. This problem could be solved by using mid-infrared (MIR) spectrometry. This technology allows a very high throughput of samples: up to 500 samples/h (Foss, 2006) and it is already used routinely by milk recording centers to predict the percentage of fat, protein, and lactose directly in milk samples. Recently, it was shown that, as long as calibration equations are available, even very small fractions, such as the fatty acids, can be predicted using MIR (Soyeurt et al., 2006). Based on these results, MIR spectrometry could be used to estimate quantitatively various traits including LF.

The aims of this study were to develop the calibration equation necessary for predicting LF by MIR spectrometry and to estimate genetic parameters for predicted LF (pLF) and its correlations with milk yield, milk fat percentage (Fat\%), milk protein percentage (Prot\%), and SCC. These latter results could give preliminary information necessary to investigate the possible association between mastitis and LF in large bovine populations and provide the first insight into the usefulness of $\mathrm{pLF}$ as an indicator of mastitis resistance.

\section{MATERIALS AND METHODS}

\section{Calibration Procedure}

Milk samples $(2 \times 60 \mathrm{~mL})$ were collected monthly from April 2005 to April 2006 from 7 herds and totaled 1,609 samples from 475 cows of 6 breeds: dual-purpose Belgian Blue (DPB), Holstein-Friesian (HOL), Jersey
(JER), Montbeliarde (MON), Normande (NOR), and non-Holstein Meuse-Rhine-Yssel type Red and White breeds (RED). The samples, taken in equal numbers from morning and evening milkings, were taken from all cows in each reference herd during the routine visits for milk recording in the Walloon region of Belgium. The first sample was analyzed on a Foss MilkoScan FT6000 (Foss, 2006; Foss, Hillerød, Denmark) to provide the spectrum, and the second sample was stored at $-26 \pm 2^{\circ} \mathrm{C}$ until the ELISA analysis. Finally, the database of 1,609 spectra was used to select the samples for calibration.

To reach the maximum of $\mathrm{LF}$ variation, the calibration samples were chosen from objective criteria considered indicators of LF concentration: Prot\%, SCC, breed, DIM, and lactation number. In total, 147 milk samples were selected and used for calibration.

The LF concentration in whole milk samples was measured in duplicate with a commercial ELISA (Bovine Lactoferrin ELISA Quantification Kit, Bethyl Laboratories Inc., Montgomery, TX), and the procedure was carried out according to the manufacturer's instructions. The samples were diluted 1:500, 1:1,000, 1:2,000, or 1:10,000 in sample buffer. The LF concentrations used for the calibration were the average of 2 measures from the same milk sample. Due to technical problems, LF estimation by ELISA for 11 samples was not completed successfully.

From the ELISA and spectral data, a specific program for multivariate calibration (WINISI III, http://www. winisi.com/) computed the calibration equation using partial least squares regression (PLS). No pretreatments were used. This regression technique requires cross-validation to prevent over-fitting. Cross-validation obtains validation errors by partitioning the calibration set into several groups (in this case: group $=1$ sample because it was a full cross-validation). A calibration is performed for each group, reserving that group for validation and calibrating groups, until every sample has been predicted once. The validation errors are combined into a standard error of cross-validation (Sinnaeve et al., 1994). Thus, to assess the efficiency of the calibration equation, different statistical parameters were estimated: mean, standard deviation (SD), standard error of calibration (SEC), calibration coefficient of determination $\left(\mathbf{R}_{\mathbf{C}} \mathbf{c}\right)$, standard error of cross-validation (SECV), and cross-validation coefficient of determination $\left(\mathbf{R}^{2} \mathbf{C V}\right)$. The ratio of SECV to SD (RPD) was also calculated (William and Norris, 2001) to estimate the efficiency of calibration. If the RPD ratio is larger than 2 , the calibration equation is considered good. On the other hand, if the RPD ratio is less than 1.5, the predictions are of poor quality and the equation cannot be used in practice (Sinnaeve et al., 1994). 
Table 1. Number of records (n), mean, and standard deviation (SD) for each analyzed component of milk in the studied cow population

\begin{tabular}{lrrr}
\hline Trait & $\mathrm{n}$ & Mean & \multicolumn{1}{c}{ SD } \\
\hline Milk (kg/d) & 39,441 & 22.17 & 8.17 \\
Fat $(\%)$ & 39,441 & 4.01 & 0.75 \\
Protein $(\%)$ & 39,441 & 3.44 & 0.39 \\
Lactoferrin (mg/L) & 7,690 & 189.08 & 155.88 \\
SCS & 39,441 & 3.03 & 1.74 \\
\hline
\end{tabular}

After analyzing results of the first calibration equation, it appeared that 7 samples with a very high concentration of LF had been not accurately predicted. The 2 values measured by ELISA for these samples were different. This could be explained by the large dilution necessary to measure these high concentrations by ELISA. Consequently, these samples were deleted. Finally, 69 samples were selected to represent the variability of LF contents in the 136 milk samples initially analyzed by ELISA.

\section{Cow Population and Milk Samples}

A total of 7,690 milk samples were collected from April 2005 to May 2006 from 1,773 cows in 25 herds and 7 breeds [Brown-Swiss (BSW), DPB, HOL, JER, MON, NOR, and RED]. All samples were analyzed on the Foss MilkoScan FT6000 during the Walloon routine milk recording, and the spectrum for each sample was recorded. Routine predictions of Fat\%, Prot $\%$, and SCC were done on a Foss MilkoScan FT6000. The SCC was transformed into SCS by the following formula: SCS = $\left[\log _{2}(\mathrm{SCC} / 100,000)\right]+3$. For milk samples with an SCC $\leq 9,000$, SCS was recorded as missing because we assumed that these very low values were due to measurement errors.

Due to technical issues, the number of observed testdays was not constant for all herds. In addition, some cows were dried off or calved during this experiment. Spectral data were used to predict the LF content. The entire test-day records, including milk yield ( $\mathrm{kg} / \mathrm{d}$; $\mathbf{M Y})$, Fat\%, Prot\%, and SCS, known for the studied cows were extracted. To add all potential contemporaries, test-day records for all cows present in the studied herd since March 2005 were also extracted. The final edited data set included 39,441 test-day records representing 1,910 cows. Test-day records with DIM less than 5 and greater than 365 were deleted. Table 1 shows the number of records, means, and SD observed in the studied cow population for MY, Fat\%, Prot\%, SCS, and pLF.

Breed composition was determined from the known pedigrees of cows. A certain percentage of genes were of unknown origin and treated as if they were provided
Table 2. Average breed composition (\%) of the studied population of cows with milk records.

\begin{tabular}{lr}
\hline Breed & Mean \\
\hline Brown-Swiss & 2.8 \\
Dual-purpose Belgian Blue & 11.6 \\
Holstein & 46.3 \\
Jersey & 3.8 \\
Montbeliarde & 11.0 \\
Non-Holstein Red and White & 4.5 \\
Normande & 13.2 \\
Unknown & 6.8 \\
\hline
\end{tabular}

by another unknown breed. Table 2 gives the average breed composition for the cows with records.

\section{Predicted Concentration of LF in Milk}

The estimated calibration equation of LF was applied to the recorded spectra to predict an indicator of the concentration of LF in milk (mg/L).

Figure 1 presents the distribution of $\mathrm{pLF}$ content in milk of the studied cow population and shows a normal distribution for this specific trait. The large variation of pLF content given in Table 2 could reflect the high variation observed during lactation or could be explained by the mix of breed composition among the studied cows.

\section{Model}

Predicted content of LF in milk was analyzed together with MY, Fat\%, Prot\%, and SCS using a multitrait animal model:

$$
\mathbf{y}=\mathbf{X} \boldsymbol{\beta}+\mathbf{W I}+\mathbf{Z} \mathbf{p}+\mathbf{Z u}+\mathbf{e}
$$

where $\mathbf{y}$ is the vector of observations (MY, Fat\%, Prot\%, $\mathrm{SCS}$, and $\mathrm{pLF}$ ); $\boldsymbol{\beta}$ is the vector of fixed effects (herd $\times$ test day $x$ class of lactation number, stage of lactation $x$ class of lactation number, class of age $\times$ class of lactation number and regressions on breed composition); $\mathbf{I}$ is the vector of permanent environment random effects within lactation; $\mathbf{p}$ is the vector of permanent environment random effects across lactations; $\mathbf{u}$ is the vector of additive genetic animal effects; $\mathbf{X}, \mathbf{W}$ and $\mathbf{Z}$ are incidence matrices; and $\mathbf{e}$ is the vector of random residual effects.

Fixed effects were defined as follows. Stage of lactation was divided in 24 classes of $15 \mathrm{~d}$. Lactations were grouped as first, second, and third or later lactation. The frequency of lactation numbers were 37.0, 25.4, and $37.6 \%$ for first, second, and third or later lactation, respectively. Age at test-day was defined as the number of months from birth. There were 9 classes of age (for first lactation, age $<29,29$ to 32 , and $\geq 33 \mathrm{mo}$; for second 


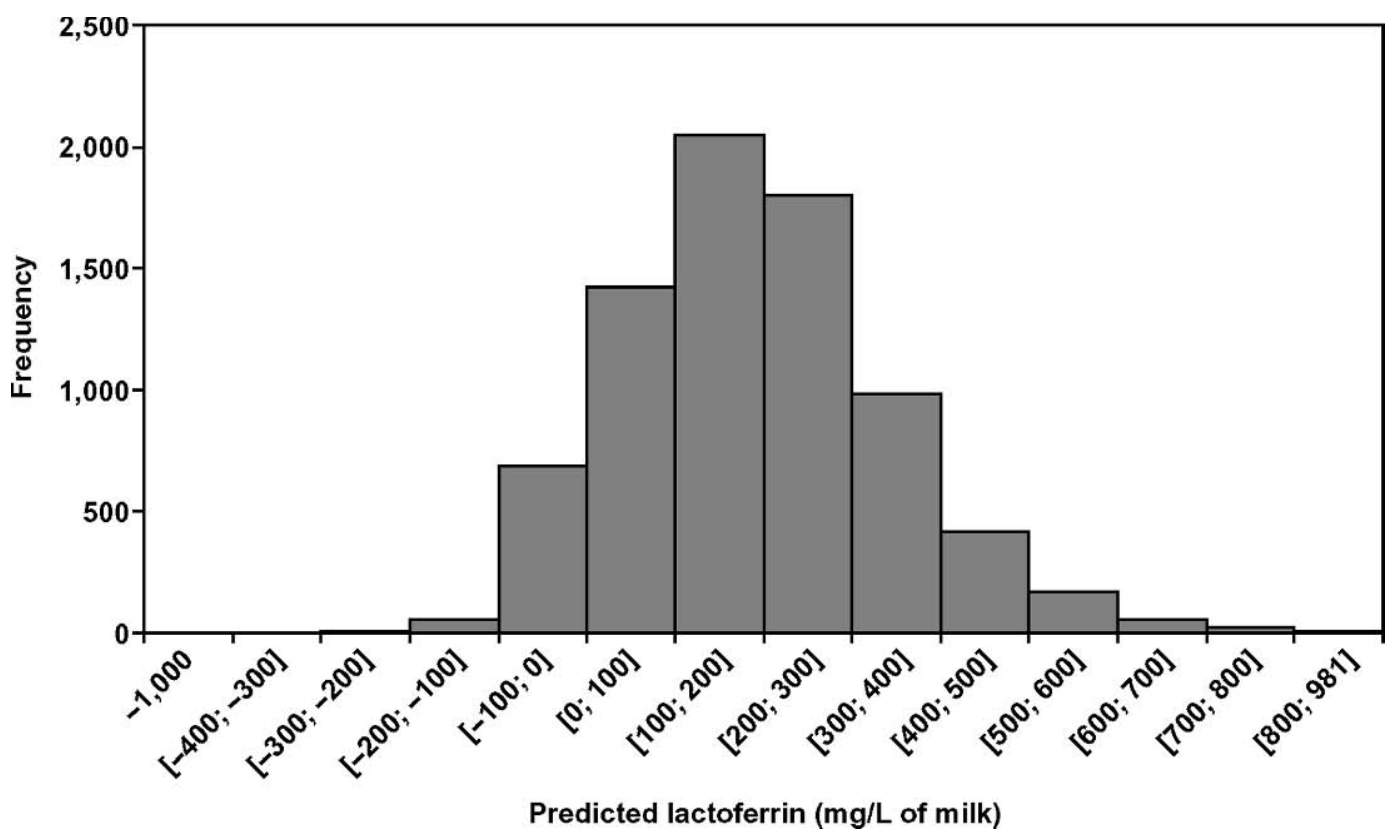

Figure 1. Distribution of the predicted lactoferrin content in milk (mg/L of milk) of the studied population.

lactation, $<42,42$ to 46 , and $\geq 47 \mathrm{mo}$; and for the third and greater lactation, age $<54,54$ to 59 , and $\geq 60 \mathrm{mo}$ ). Results for regression on breed composition were recorded and compared with the reference Holstein breed.

Pedigree completeness was good with 18,856 animals in the pedigree of the cows with records. Due to this informative pedigree, genetic and permanent environmental effects could be separated. Variance components were estimated using expectation maximization REML (Misztal, 2007) and average information REML (AIREML; Misztal, 2007). Standard errors of estimates were obtained by AI-REML (Misztal, 2007).

\section{RESULTS AND DISCUSSION}

\section{Calibration Equation}

The applied PLS analysis resulted in an equation with 7 factors combining 511 values. The means of samples used for the calibration was $253.72 \mathrm{mg}$ of $\mathrm{LF} / \mathrm{L}$ (SD = $206.37 \mathrm{mg}$ of $\mathrm{LF} / \mathrm{L}$ ). The SEC and $\mathrm{R}^{2} \mathrm{c}$ estimated for the calibration procedure were $85.96 \mathrm{mg}$ of $\mathrm{LF} / \mathrm{L}$ and $82.65 \%$, respectively. The SECV and $\mathrm{R}^{2} \mathrm{cv}$ estimated during the full cross-validation were $103.93 \mathrm{mg}$ of LF/ $\mathrm{L}$ and $75.0 \%$, respectively. Thus, the RPD was equal to 1.98. Hence, because the RPD ratio was close to 2 , the results given by the calibration equation can be considered as good predictors of the LF content in bovine milk estimated by ELISA.

To check if the pLF obtained by MIR was due to a real absorbance of the specific LF molecule and not an artifact due to correlations between LF predicted by ELISA and other milk components, the correlations between LF and the constituents estimated on the MilkoScan FT6000 (Fat\%, Prot\%, urea, SCC, lactose, free fatty acids content, or concentration of DM) were estimated and are given in Table 3 . As the $R_{\mathrm{CV}}$ values were higher than the values of the correlations, the LF calibration equation can be considered the result of a real absorbance in MIR region.

Figure 2 presents the cross-validation results from 69 milk samples and shows that the ability of the calibration equation to predict low LF content was poorest compared with the prediction of greatest LF concentration. In fact, for the low LF contents measured by ELISA, Figure 2 shows a cloud of data points. However, the calibration equation estimated in this research to predict the LF content in milk seems to give good indica-

Table 3. Correlations between the lactoferrin content (LF) estimated by ELISA and the different components of bovine milk estimated by using the MilkoScan FT6000 (Foss, Hillerød, Denmark) and square root of the cross-validation coefficient of determination (Rcv)

\begin{tabular}{lcc}
\hline Trait & $\begin{array}{c}\text { Correlation } \\
\text { with LF }\end{array}$ & Rcv \\
\hline Fat $(\%)$ & 0.15 & 0.87 \\
Protein $(\%)$ & 0.56 & 0.87 \\
SCC & 0.44 & 0.87 \\
Urea $(\mathrm{g} / 100 \mathrm{~mL})$ & 0.35 & 0.87 \\
Free fatty acids $(\mathrm{mmol} / 100 \mathrm{~g}$ of fat) & 0.24 & 0.87 \\
Lactose $(\mathrm{g} / 100 \mathrm{~mL})$ & -0.33 & 0.87 \\
DM $(\%)$ & 0.35 & 0.87 \\
\hline
\end{tabular}




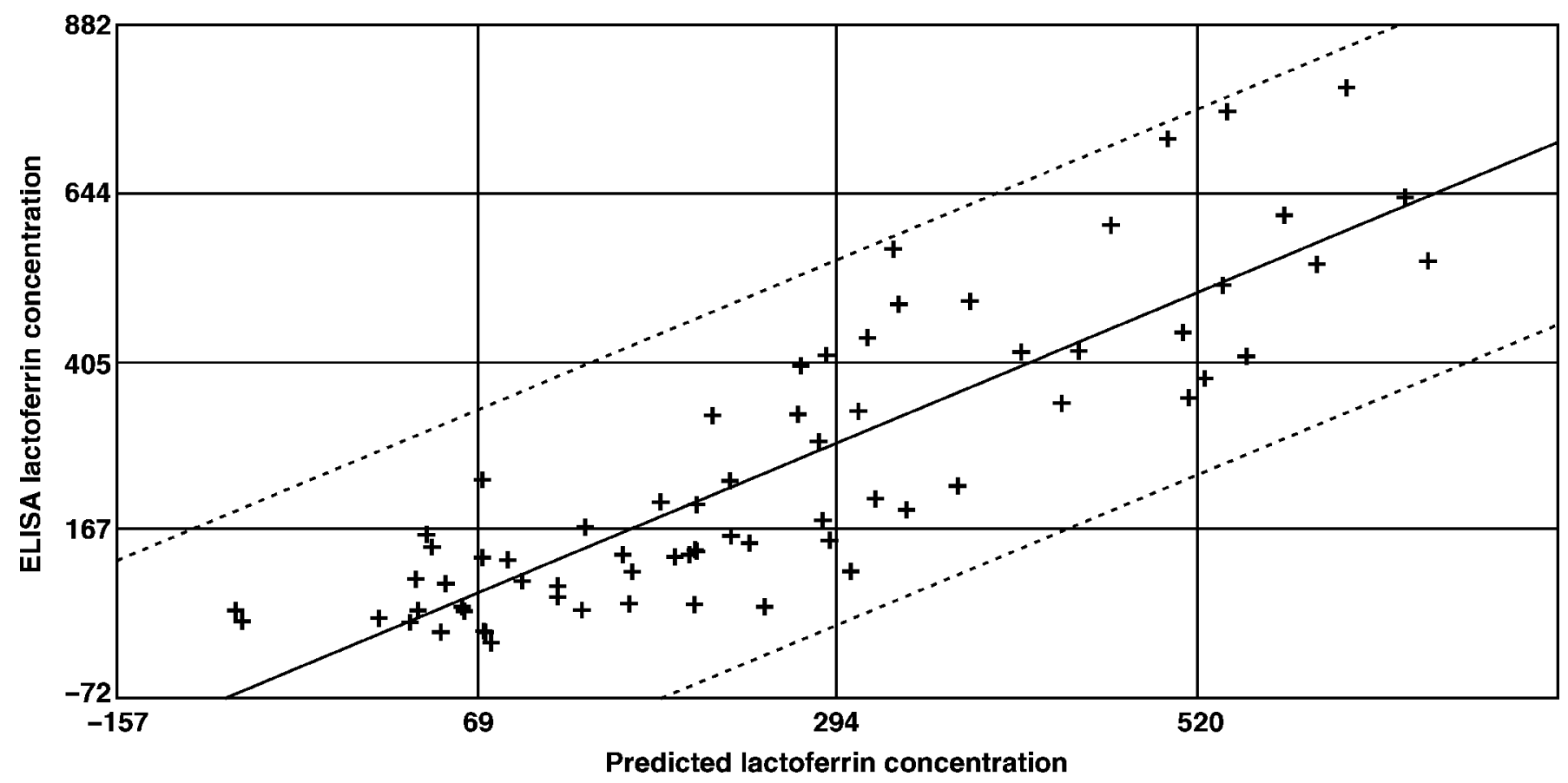

Figure 2. Cross-validation results applied to 69 milk samples (dotted lines: standard error of cross-validation; solid line: perfect prediction, where concentration estimated by reference analysis = concentration estimated by infrared analysis).

tors of the LF content in milk ( $\mathrm{pLF})$. Therefore, it would be interesting to use this equation to estimate $\mathrm{pLF}$ in the milk of cows that take part in milk recording programs.

\section{Effects of DIM and Lactation Number}

Figure 3 shows the trajectory of mean pLF content during the lactation for cows in first, second, and third or later lactation. The pLF content increased during lactation, suggesting that the LF content in cow's milk could increase during the lactation. This trend has also been shown by Gaunt et al. (1980) even though the greatest concentration in LF was observed during the dry period. More recently, Hagiwara et al. (2003) indicated that the mean milk LF concentration at the end of lactation tended to be higher than that at the peak or during mid lactation. However, these authors observed a slight increase of LF content in cow's milk with increasing DIM. Martin et al. (2003) found that the stage of lactation was not important for LF content when cows with 10 or fewer DIM were eliminated. However, in this study (Figure 3) and that of Gaunt et al. (1980), the increase of LF during the lactation appeared to be linear. This divergence of observations could be explained by the number of milk samples. Martin et al. (2003) took only one 60-mL sample from 180 Holstein cows. In this study, the prediction of LF content has been repeated for many dairy cows.
According to Figure 3, pLF content seems to be higher in the milk of older cows. This result may suggest that age would have a positive impact on the production of LF by dairy cows. This relationship was also observed by Martin et al. (2003) and Tsuji et al. (1990). On the other hand, Hagiwara et al. (2003) observed a negative effect of age on the LF content in milk. The difference in observations could be explained by the low number of samples analyzed for each year of age by Hagiwara et al. (2003; 20,43, 20,24, and 4 for $2,3,4,5$, and $6 \mathrm{yr}$ of age, respectively) compared with the current study.

\section{Breed Differences}

Table 4 presents the differences in pLF content between HOL and 6 dairy breeds: BSW, DPB, JER, MON, NOR, and RED, together with the corresponding $P$ values.

According to a Student's $t$-test, the pLF content in JER milk was significantly greater than in HOL milk (Table 4). Tsuji et al. (1990) indicated that JER colostrum contains more LF content than HOL colostrum.

All other studied dairy breeds showed mean pLF between that of JER and HOL, except for RED, for which pLF was the lowest. However, these differences approached significance only for RED.

\section{Heritability and Genetic Correlations}

Table 5 presents the estimates of variance ratios (as a percentage of phenotypic variance) and the corres- 


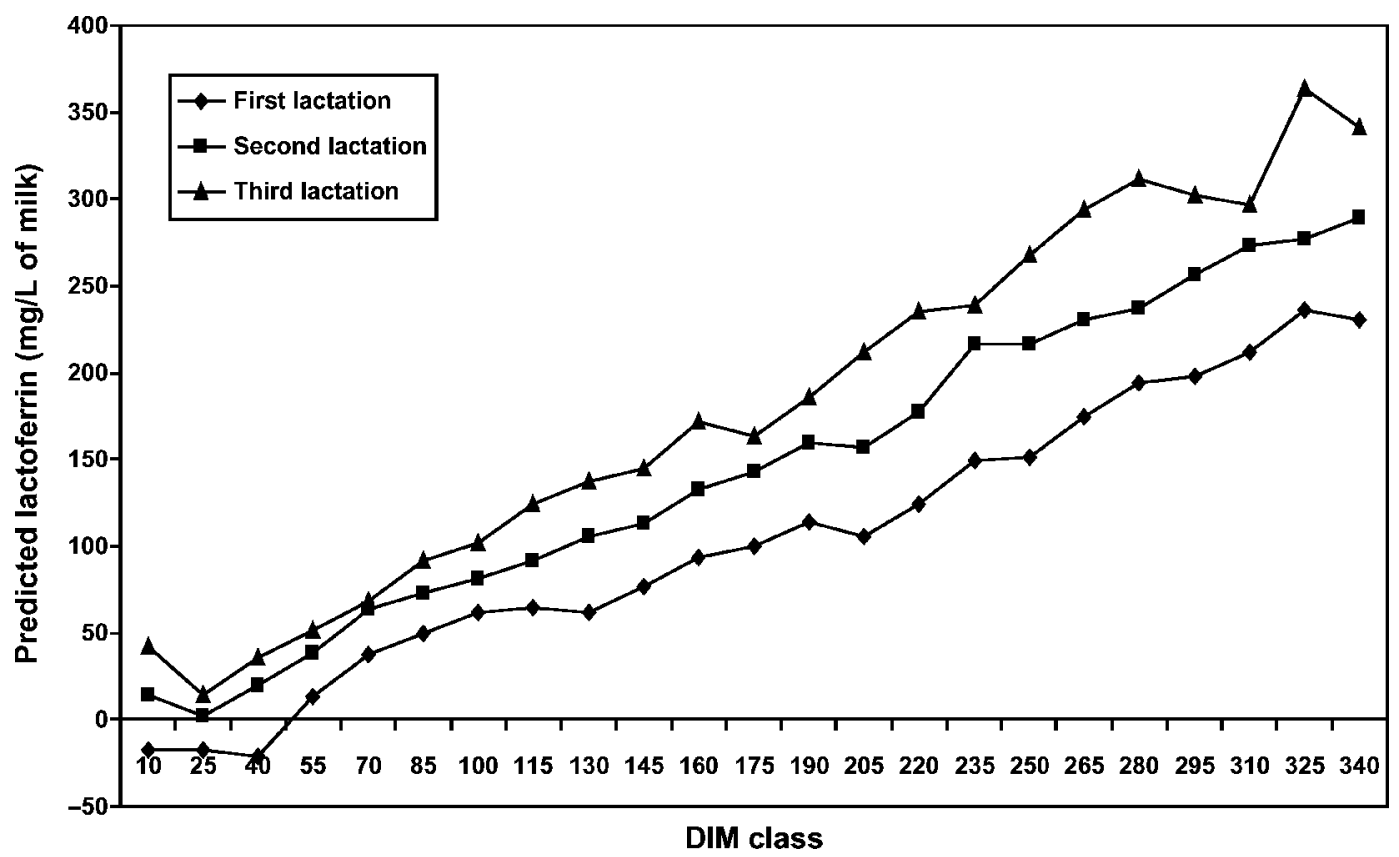

Figure 3. Effect of the class of DIM (represented by mid-point of the class) and lactation number on lactoferrin content (mg/L).

ponding standard errors (SE) for each random effect (genetic, permanent environments within and across lactations, and residual).

The estimated heritabilities were $18.8,31.2$, and $28.2 \%$ for MY, Prot\%, and Fat\%, respectively (Table 5). The heritability for MY was similar to values estimated by other authors for test-day yield using other models (e.g., Veerkamp and Goddard, 1998; Lidauer and Mäntysaari, 1999; Gengler et al., 2004). The heritability estimated for SCS was $12.1 \%$. This value is close to that given by Interbull (2006) for Holstein dairy cattle in Belgium (13.5\%). The heritability estimated for $\mathrm{pLF}$ was $19.7 \%$ ( $\mathrm{SE}=3.06 \%$; Table 5 ). Very few studies have given the heritability of LF in bovine milk. The heritability estimated from the current study for the indicator of LF and the LF heritability estimated previously by Klobasa et al. (1977) on 114 cows (35\%) were both in the moderate range. Gaunt et al. (1980) reported a relatively high value for the heritability of $\mathrm{LF}$ of $43.8 \%$

Table 4. Differences between the means of predicted lactoferrin content in milk $(\mathrm{mg} / \mathrm{L})$ for several breeds and the Holstein, and the associated $P$-values

\begin{tabular}{lcc}
\hline Breed & Difference & $P$-value \\
\hline Brown-Swiss & 15.73 & 0.19 \\
Dual-purpose Belgian Blue & 11.67 & 0.26 \\
Jersey & 31.21 & 0.04 \\
Montbeliarde & 18.39 & 0.15 \\
Non-Holstein Red and White & -20.11 & 0.09 \\
Normande & 14.40 & 0.13 \\
\hline
\end{tabular}

but their SE was very large (30.4\%). Heritability close to $20 \%$ for pLF in cow milk is promising and suggests that selection for an increasing content of LF in bovine milk is possible. Based on the known effects of LF on the immune system, this selection could have a positive impact on mastitis resistance. Further research is needed to study possible associations between mastitis and LF. Moreover, the genetic approach to increase the LF content in milk could be useful because Turner and Thomson (2006) have shown that the quantity of feed distributed to cows did not change the LF content in milk. Therefore, the nutritional impact on LF content in milk seems to be limited.

As for the other studied traits, the within-lactation variation of $\mathrm{pLF}$ was more important than that estimated across lactations (Table 5).

Table 6 presents the genetic and phenotypic correlations calculated between MY, Fat\%, Prot\%, pLF, and SCS. Estimated genetic correlations between MY and Fat $\%, \mathrm{MY}$ and Prot $\%$, and Fat\% and Prot $\%$ were -0.33 $(\mathrm{SE}=0.07),-0.45(\mathrm{SE}=0.08)$, and $0.60(\mathrm{SE}=0.07)$, respectively. These genetic correlations are in agreement with Roman and Wilcox (2000). In fact, these authors showed that the genetic correlation between MY and Fat\% was -0.21 and between MY and Prot\% was -0.56 . These same authors also showed that the genetic correlation between Fat\% and Prot\% was 0.63. The estimated genetic correlations for traditional production traits were similar to those showed by Othmane et al. (2004). 
Table 5. Estimates of heritability and ratios of permanent environmental and residual variances as percentage of phenotypic variance, together with the corresponding standard error (SE), for milk yield, milk fat percentage, milk protein percentage, predicted lactoferrin $(\mathrm{pLF})$ content, and SCS

\begin{tabular}{|c|c|c|c|c|c|c|c|c|c|}
\hline \multirow[b]{3}{*}{ Trait } & & & \multicolumn{4}{|c|}{ Permanent environment } & & & \multirow{3}{*}{$\begin{array}{l}\text { Phenotypic } \\
\text { variance }\end{array}$} \\
\hline & \multicolumn{2}{|c|}{ Heritability } & \multicolumn{2}{|c|}{ Within lactation } & \multicolumn{2}{|c|}{ Across lactations } & \multicolumn{2}{|c|}{ Residual } & \\
\hline & Estimate & SE & Estimate & $\mathrm{SE}$ & Estimate & SE & Estimate & $\mathrm{SE}$ & \\
\hline Milk (kg/d) & 18.8 & 2.24 & 30.6 & 0.73 & 8.13 & 1.92 & 42.3 & 0.25 & 20.00 \\
\hline Fat $(\%)$ & 31.2 & 2.35 & 4.9 & 0.26 & 5.68 & 1.73 & 58.2 & 0.34 & 0.33 \\
\hline Protein $(\%)$ & 28.2 & 2.48 & 11.6 & 0.38 & 9.28 & 1.95 & 50.8 & 0.30 & 0.07 \\
\hline $\mathrm{pLF}(\mathrm{mg} / \mathrm{L})$ & 19.7 & 3.06 & 22.0 & 2.15 & 6.18 & 3.25 & 52.1 & 0.72 & 10,188 \\
\hline SCS & 12.1 & 1.77 & 29.6 & 0.72 & 7.18 & 1.59 & 51.1 & 0.30 & 2.36 \\
\hline
\end{tabular}

The genetic correlation between PROT and $\mathrm{pLF}$ was moderate (0.50; $\mathrm{SE}=0.09$; Table 6). This is logical because LF is a protein present in milk. This value confirms the importance of choosing the samples for the calibration based on the percentage of protein. The estimated genetic correlation between MY and pLF (-0.36, $\mathrm{SE}=0.10)$ was similar to that estimated between MY and Prot $\%$. This could be explained by a dilution effect already observed for Fat\% (Lock and Garnsworthy, 2003). On the other hand, the genetic correlation between Fat\% and pLF (0.33, SE = 0.08) was lower than that estimated with Prot\%. The genetic correlations estimated between different milk components should also reflect the similarities in the metabolic production system. Therefore, the genetic correlation of $0.04(\mathrm{SE}=$ 0.11 ) estimated between SCS and pLF could indicate that the production of LF and SCS in milk present genetically different processes. However, the low positive phenotypic correlation between SCS and $\mathrm{pLF}(0.26$, $\mathrm{SE}=0.09$ ) seems to show that if the SCS increase, the LF content in milk also tends to increase. Because it is known that SCS increases in the presence of mastitis (e.g., Koivula et al., 2005), the positive phenotypic association between SCS and pLF could indicate the effect of mastitis on LF. Moreover, this observation could confirm the previous conclusions of many researchers about the increase of LF (compared with the normal level of LF in healthy cows) in the presence of mastitis (e.g., Harmon et al., 1976; Hagiwara et al., 2003; Martin et al., 2003).

Table 6. Genetic (above the diagonal) and phenotypic (below the diagonal) correlations between milk yield, milk fat percentage, milk protein percentage, predicted lactoferrin content $(\mathrm{pLF})$, and SCS

\begin{tabular}{lcccrr}
\hline Trait & Milk & Fat & Protein & pLF & SCS \\
\hline Milk (kg/d) & & -0.33 & -0.45 & -0.36 & -0.02 \\
Fat $(\%)$ & -0.18 & & 0.60 & 0.33 & 0.06 \\
Protein $(\%)$ & -0.32 & 0.39 & & 0.50 & -0.08 \\
pLF (mg/L) & -0.28 & 0.12 & 0.39 & & 0.04 \\
SCS & -0.17 & 0.07 & 0.13 & 0.26 & \\
\hline
\end{tabular}

The MIR method is fast, inexpensive and can be directly integrated into routine milk recording to enable the study of normal levels of LF produced by a cow. Hence, it could be possible to predict the expected level of LF that a cow would produce in healthy status at a given lactation stage. Thus, the comparison between the pLF level in milk predicted by MIR at a given time and the expected LF concentration for the same healthy cow at the same time might be an indicator of mastitis. Thus, LF predicted by MIR could be a useful tool for the farmer to check the status of mammary glands in their herd. Second, the known LF effects on the immune system and its natural production by healthy cows could permit one to formulate the hypothesis that LF content could be an indicator for resistance to mastitis. These observations give new perspectives and suggest new avenues of research in mastitis detection and genetic improvement of mastitis resistance in dairy cows.

\section{CONCLUSIONS}

The prediction of an indicator of $L F$ content $(\mathrm{pLF}$ ) in milk by MIR spectrometry investigated in the current study provides a new perspective to check the sanitary status of mammary glands in herds. The $\mathrm{R}^{2} \mathrm{cv}$ and RPD ratios estimated after the PLS calibration procedure were $75.1 \%$ and 1.98 , respectively. Based on these results, the estimated pLF can be considered a good indicator of LF content in bovine milk. Stage of lactation and lactation number influence the LF concentration in bovine milk. Small differences in pLF content were observed across 7 dairy breeds. The heritability obtained for pLF (19.70\%) suggests that genetic selection could be effective for increasing the LF content in milk. The genetic and phenotypic correlations observed between SCS and pLF were 0.04 and 0.26 , respectively. As SCS increases in the presence of mastitis, this observation seems to indicate that $\mathrm{pLF}$ (or a function between observed and expected pLF) could be an indicator of mastitis. However, these correlations, especially the genetic correlation, were low and support the proposal 
that more research is needed on the relationship between LF and mastitis resistance.

\section{ACKNOWLEDGMENTS}

The first author acknowledges the support of FRIA through a grant scholarship. Additional support was provided through grants $2.4507 .02 \mathrm{~F}$ (2) and F.4552.05 of the National Fund for Scientific Research. The authors gratefully acknowledge the support of the Walloon Breeding Association (AWE), the Walloon Milkcomite, manuscript review by Matt Spangler (University of Georgia, Athens), and the provincial farm "Ferme de la Haye." Partial financial support of this project by the Walloon Regional Ministry of Agriculture (Ministère de la Région Wallonne, Direction Générale de l'Agriculture) is also acknowledged.

\section{REFERENCES}

Baker, E. N. 2005. Lactoferrin: A multi-tasking protein par excellence. Cell. Mol. Life Sci. 62:2529-2530.

Baker, E. N., and H. M. Baker. 2005. Molecular structure, binding properties and dynamics of lactoferrin. Cell. Mol. Life Sci. 62:2531-2539.

Baker, H. M., and E. N. Baker. 2004. Lactoferrin and iron: Structural and dynamic aspects of binding and release. Biometals 17:206216.

Baumrucker, C. R. 2000. Mammary mechanisms for lactoferrin: Interactions with IGFBP-3. Biotechnol. Agron. Soc. Environ. 4:5-12.

Baumrucker, C. R., F. Schanbacher, Y. Shang, and M. H. Green. 2005. Lactoferrin interaction with retinoid signaling: Cell growth and apoptosis in mammary cells. Domest. Anim. Endocrinol. 30:289-303.

Baveye, S., E. Elass, J. Mazurier, G. Spik, and D. Legrand. 1999. Lactoferrin: A multifunctional glycoprotein involved in the modulation of the inflammatory process. Clin. Chem. Lab. Med. $37: 281-296$

Brock, J. 1995. Lactoferrin: A multifunctional immunoregulatory protein? Immunol. Today 16:417-419.

Farnaud, S., and R. W. Evans. 2003. Lactoferrin - A multifunctional protein with antimicrobial properties. Mol. Immunol. 40:395-405.

Foss. 2006. MilkoScanTM FT6000. http://www.foss.dk/Solutions/ ProductsDirect/MilkoScanFT6000.aspx Accessed Nov. 2, 2006.

Gaunt, S. N., N. Raffio, E. T. Kingsbury, R. A. Damon, W. H. Johnson, and B. A. Mitchell. 1980. Variation of lactoferrin and mastitis and their heritabilities. J. Dairy Sci. 63:1874-1880.

Gengler, N., G. T. Wiggans, and A. Gillon. 2004. Estimated heterogeneity of phenotypic variance of test-day yield with a structural variance model. J. Dairy Sci. 87:1908-1916.

Hagiwara, S.-I., K. Kawai, A. Anri, and H. Nagahata. 2003. Lactoferrin concentrations in milk from normal and subclinical mastitis cows. J. Vet. Med. Sci. 65:319-323.

Harmon, R. J., F. L. Schanbacher, L. C. Ferguson, and K. L. Smith. 1976. Changes in Lactoferrin, immunoglobulin G, bovine serum albumin, and $\alpha$-lactalbumin during acute experimental and natural coliform mastitis in cows. Infect. Immun. 13:533-542.

Interbull. 2006. Genetic evaluation: Udder health. http://www. interbull.slu.se/udder/framesida-udder.htm Accessed Oct. 31, 2006.
Klobasa, F., B. Senft, F. Meyer, and U. E. Pfleiderer. 1977. Untersuchungen uber Lactoferrin and Immoglobulin G in der Kuhmilch. 2. Mitteilung: die Konzentration von Lactoferrin and Immunoglobulin G in Abhangigkeit von der Laktationsnummer, vom Alter sowie genetische Aspekte dieser Protein. Zuchtungskunde 49:110-119.

Koivula, M., E. A. Mäntysaari, E. Negussie, and T. Serenius. 2005. Genetic and phenotypic relationships among milk yield and somatic cell count before and after clinical mastitis. J. Dairy Sci. 88:827-833.

Kutila, T., L. Suojala, T. Lehtolainen, H. Saloniemi, L. Kaartinen, M. Tähti, K. Seppälä, and S. Pyörälä. 2004. The efficacy of bovine lactoferrin in the treatment of cows with experimentally induced Escherichia coli mastitis. J. Vet. Pharmacol. Therap. 27:197-202.

Lidauer, M., and E. A. Mäntysaari. 1999. Multiple-trait reduced rank random regression test-day model for production traits. Proc. 1999 Interbull Meeting, Zurich, Switzerland. Interbull Bull. 22:74-80.

Lock, A. L., and P. C. Garnsworthy. 2003. Seasonal variation in milk conjugated linoleic acid and $\Delta^{9}$-desaturase activity in dairy cows. Livest. Prod. Sci. 79:47-59.

Martin, A. A., M. A. Faust, L. J. Rowe, and E. J. Lonergan. 2003. Associations of lactoferrin concentrations in milk with indicators of mastitis in dairy cows. J. Dairy Sci. 86(Suppl. 1):129. (Abstr.)

Mead, P. E., and J. W. Tweedie. 1990. cDNA and protein sequence of bovine lactoferrin. Nucleic Acids Res. 18:7167.

Misztal, I. 2007. BLUPF90 family of programs. University of Georgia, Athens. http://nce.ads.uga.edu/ ignacy/numpub/blupf90/ Accessed Jan. 2, 2007.

Othmane, M. H., M. Ben Hamouda, and H. Hammami. 2004. Multivariate animal model estimates of genetic, environmental and phenotypic correlations for early lactation milk yield and composition in Tunisian Holstein-Friesians. Proc. 2004 Interbull Meeting, Sousse, Tunisia. Interbull Bull. 32:129-132.

Pierce, A., D. Colavizza, M. Benaissa, P. Maes, A. Tartar, J. Montreuil, and G. Spik. 1991. Molecular cloning and sequence analysis of bovine lactotransferrin. Eur. J. Biochem. 196:177-184.

Pugovel, G., C. R. Baumrucker, H. Sauerwein, R. Rühl, E. Ontsouka, H. M. Hammon, and J. W. Blum. 2005. Effects of an enhanced vitamin A intake during the dry period on retinoids, lactoferrin, IGF system, mammary gland epithelial cell apoptosis, and subsequent lactation in dairy cows. J. Dairy Sci. 88:1785-1800.

Roman, R. M., and C. J. Wilcox. 2000. Bivariate animal model estimates of genetic, phenotypic, and environmental correlations for production, reproduction, and somatic cells in Jerseys. J. Dairy Sci. 83:829-835.

Sinnaeve, G., P. Dardenne, R. Agneessens, and R. Biston. 1994. The use of near infrared spectroscopy for the analysis of fresh grass silage. J. Near Infrared Spectrosc. 2:79-84.

Soyeurt, H., P. Dardenne, G. Lognay, D. Veselko, P. Mayeres, and N. Gengler. 2006. Estimating fatty acid content in cow milk using mid-infrared spectrometry. J. Dairy Sci. 89:3690-3695.

Tsuji, S., Y. Hirata, and F. Mukai. 1990. Comparison of lactoferrin content in colostrum between different cattle breeds. J. Dairy Sci. $73: 125-128$.

Turner, S.-A., and N. A. Thomson. 2006. Lactoferrin in bovine milk is not affected by strain of cow or level of feed. 7th Int. Conf. Lactoferrin, Canada. 84(3):393. (Abstr.)

Veerkamp, R. F., and M. E. Goddard. 1998. Covariance functions across herd production levels for test day records on milk, fat and protein yields. J. Dairy Sci. 81:1690-1701.

Ward, P. P., E. Paz, and O. M. Conneely. 2005. Multifunctional roles of lactoferrin: A critical overview. Cell. Mol. Life Sci. 62:2540-2548.

William, P., and K. Norris. 2001. Near-infrared technology in the agricultural and food industries. American Association of Cereal Chemists, St. Paul, MN. 